\title{
O DESFILE DO BOI NEON: ARQUIVOS EM MOVIMENTO ${ }^{1}$
}

\author{
Rodrigo S. Fontanini de Carvalho \\ PUC-Campinas \\ rodrigosfc@uol.com.br \\ Ricardo Gaiotto de Moraes \\ PUC-Campinas \\ rgaiotto@gmail.com
}

\begin{abstract}
RESUMO
Um arquivo não é imóvel, mas um conjunto de rastros que são ressignificados, na sincronia do processo de memória. O filme constitui-se como narrativa cuja tessitura se dá a partir de arquivos. Posto isso, este artigo propõe uma leitura do filme brasileiro Boi neon (2016), dirigido por Gabriel Mascaro. A representação da ambiguidade do protagonista, entre os gestos rústicos no preparo dos bois nas vaquejadas do interior do nordeste e a sensibilidade do design de roupas femininas, parece constituir uma masculinidade multifacetada, o que confronta o arquivo de um paradigma heteronormativo das performatividades de gênero. Essas novas perspectivas parecem possibilitar (re)escritas e (des)contextualizações dos arquivos sobre esses sujeitos outrora legados à opressão.
\end{abstract}

PALAVRAS-CHAVE: Boi neon. Gênero. Arquivo. Corpo.

\section{THE NEON BULL PARADE: FILES ON MOVEMENT}

\begin{abstract}
Based on the idea that an archive is not a static building, it is composed, however, by a set of traces that have been re-signified following the memory process, this article aims to analyze the Brazilian movie Neon Bull (2016), directed by Gabriel Mascaro, on a perspective in which a film can (de)construct archives. While Neon's protagonist, spent part of his day grooming animals to the vaquejada, a rodeo sport common in the North East of Brazil, he uses his spare time to design costumes. This ambiguity seems to constitute multifaceted masculinity, which confronts the archive of a heteronormative paradigm on performing gender. These new perspectives enable (re)writing and (de)contextualization of the archives on these subjects, guaranteeing resistance against oppression.
\end{abstract}

Keywords: Neon Bull. Gender. Archive. Body.

\section{O DESFILE DE BOI NEÓN: ARCHIVOS EM MOVIMENTO}

\section{RESUMEN}

Basado en la idea de que un archivo no es un edificio estático, pero está compuesto por un conjunto de huellas que han sido re-significadas siguiendo el proceso de memoria, este artículo pretende analizar la película brasileña Boi Neon (2016), dirigida por Gabriel Mascaro,

\footnotetext{
${ }^{1}$ Texto originário de pesquisa financiada pela CAPES.
} 
en una perspectiva en la que una película puede (de)construir archivos. Mientras que el protagonista de Neon pasaba parte de su día preparando animales a la vaquejada, un deporte de rodeo común en el Nordeste de Brasil, utiliza su tiempo libre para diseñar trajes. Esta ambigüedad parece constituir una masculinidad multifacética, que confronta el archivo de un paradigma heteronormativo sobre el género. Estas nuevas perspectivas permiten la (re)escritura y (des)contextualización de los archivos sobre estos temas, garantizando la resistencia contra la opresión.

Palabras claves: Boi Neon. Género. Archivo; Cuerpo.

\section{LE DEFILE DE BOI NEÓN: DEPLACEMENT DE FICHIERS}

\section{RÉSUMÉ}

Un fichier n'est pas immobile, mais un ensemble de pistes qui sont réinterprété dans le processus de la mémoire. Les films sont produits comme une narration dont les tessitures sont fabriqués à partir de fichiers. Cela dit, cet article propose une lecture du film brésilien Rodéo (2016), dirigé par Gabriel Mascaro. La représentation de l'ambiguïté du personnage principal est une masculinité aux multiples facettes, entre les gestes rustiques pour préparer le bétail aux vaquejadas à l'intérieur du Nord-Est et la sensibilité de la conception de vêtements pour femmes, qui confronte le fichier d'un paradigme hétéronormatif de performativités de genre. Ces nouvelles perspectives permettre de (re)écrit et (un)contextualisation des fichiers sur ces sujets, qui garantit une résistance contre l'oppression.

Mots-clés: Rodéo. Genre. Fichier. Corps.

\section{INTRODUÇÃO}

Um arquivo, em sua concepção mais imediata de lugar onde se guardam objetos do passado, não é um imóvel de memórias que resiste ao tempo. É, antes, um conjunto de rastros que vão sendo ressignificados, na sincronia contingente do processo de memória, à medida que é manipulado tanto por aqueles que, em um passado, guardaram e organizaram os registros, quanto por aqueles que, no presente, reviram e reorganizam narrativas a partir de marcas guardadas e que as inscrevem em "telas" (SOLIS, 2014, p. 374) de variados entrelaçamentos. Guardar, (re)organizar, narrar são ações recortadas pela ideologia e pelos jogos de poder, o que historiciza o processo de arquivamento e a tessitura das narrativas daí advindas, embaralhando a própria impressão de origem que poderia impregnar a ideia de arquivo.

Dentre essas "telas", pode-se incluir o cinema. Considerando os mais variados gêneros desta arte, o filme constitui-se como uma narrativa cuja tessitura se forma a partir de arquivos, uma vez que a produção cinematográfica manipula um conjunto de materiais que abrange das referências ao próprio cinema às apropriações de dados dos mais variados registros da ficção 
e da realidade. Para além do acesso a múltiplos arquivos, o filme, como objeto manipulado, constitui-se, ele mesmo, em elemento arquivável.

É, a partir desta perspectiva, que se propõe neste artigo uma leitura do filme brasileiro Boi neon ${ }^{2}$, do diretor e roteirista Gabriel Mascaro, lançado em 2016. Nesta narrativa, o título já sugere a representação da aparente ambiguidade do protagonista entre os gestos rústicos advindos da lide que exerce preparando os bois nas vaquejadas do interior do sertão nordestino, e a sensibilidade do costureiro, movida pelo desejo se tornar um estilista. Para além do título, pode-se verificar, na superfície da sucessão narrativa, um protagonista cuja representação beira a de uma masculinidade liberal e poliédrica (ZURIAN, 2015, loc 408); no subterrâneo dos pressupostos, uma personagem que não corresponde às representações heteronormativas do heterossexual ou do homossexual. Se, no segundo caso, o filme confronta as expectativas de parte de um público espectador ainda acostumado a padrões binários de identificação de gênero, reencenando os modos do homem do sertão e recolocando as peças de um arquivo antes organizado de forma machista, no primeiro caso, como objeto a ser arquivado, Boi neon instaura um novo arranjo pautado na representação do entre-lugar e de reconhecimento da performatividade de gênero.

\section{DESENVOLVIMENTO TEÓRICO E ANÁLISE DO FILME}

Inicialmente, é preciso compreender as diversas noções de arquivo, exploradas por Jacques Derrida no texto Mal de Arquivo (2001) para que, finalmente, sejam associadas ao cinema. Uma delas condiz com a ideia de o arquivo ser um depósito de dados que serve como "evidência”, indício - neste caso, refere-se ao lugar "onde as coisas começam”: “o vocábulo [arquivo] remete bastante bem, como temos razões de acreditar, ao arkhê no sentido físico, histórico ou ontológico; isto é, ao originário, ao primeiro, ao principal, ao primitivo, em suma, ao começo" (DERRIDA, 2001, p. 12). Essa visão de arquivo é similar à abordagem feita por Le Goff (1990) na comparação entre monumento e documento: "resume-se a um conjunto de documentos que, em sua materialidade, representam fatos históricos e verdades de uma tradição, isto é, um monumento que marca a experiência histórica” (LE GOFF, 1990, p. 535).

Quando se parte deste princípio, induz-se ao sentido de verdade, de confiabilidade, pois o arquivo forma-se de informações, fatos, acontecimentos válidos e evidentes, servindo como

\footnotetext{
${ }^{2}$ Boi neon, filme de Gabriel Mascaro, lançado no Brasil em 2016 pela produtora Desvia Filmes. Vencedor do prêmio especial do júri, no Festival de Veneza; Melhor filme, fotografia, atriz coadjuvante e roteiro, no Festival do Rio; Menção honrosa no Festival de Toronto.
} 
guardião, o que alude à visão clássica de "protetor". Isso significa que o arquivo guarda, protege algo que possa vir a ser revelado ou dito, daí, por exemplo, os discursos filosóficos, as diversas áreas do saber e do discurso científico (ambos ligados à racionalidade) serem colocados nessa linha de pensamento tradicional do arquivo como um depósito do conhecimento, de onde parte principalmente o campo teórico da história.

Contudo, é impossível pensar no arquivo sendo constituído de uma "massa documental fixa e congelada", tendo o passado como único registro temporal (BIRMAN, 2008, p. 109). Disso decorre, então, a segunda concepção de arquivo, cuja relação com a questão a ser aqui desenvolvida é mais interessante: o conceito de "mal de arquivo" (DERRIDA, 2001).

Tal conceito inscreve-se na contemporaneidade, sobretudo, graças a um contexto histórico marcado por inúmeras desconstruções dos arquivos sobre o mal. Deve-se contrapor esta visão à primeira no sentido de que a leitura crítica do arquivo propõe sua desconstrução. Nas palavras de Birman (2008, p. 109),

\footnotetext{
Empreender a leitura crítica do arquivo e propor a sua desconstrução, que já se realiza efetivamente no campo da história contemporânea pela abertura dos múltiplos arquivos sobre o mal, implica não apenas uma interpretação do passado da tradição ocidental, mas principalmente na sua possível abertura para o futuro.
}

A leitura de um arquivo desdobra-se, assim, em três tempos concomitantes: o presente passado, o presente atual e o presente futuro, que demarcam simultaneamente uma dimensão de finitude, existente na temporalidade do arquivo, e uma infinitude, reiterada na repetição do ato arquivante, "na medida em que o arquivo, enquanto tal, implicaria fundamentalmente a perspectiva do futuro e a sua insistente abertura para o vir-a-ser" (BIRMAN, 2008, p. 110).

O termo "mal de arquivo" estabelece um diálogo com o contexto histórico contemporâneo (dos desastres e do caos), pois são colocados em evidência os "arquivos do mal", aqueles, ao longo do tempo, dissimulados, manipulados e até destruídos. Derrida explora o sentido da palavra arkhé como origem e contenção do poder e relaciona-a à noção de arquivo como memória pessoal e histórica, levando em conta a obra de Freud. Derrida, citando a dificuldade de se trabalhar com o conceito de arquivo - uma vez que ele representa a hierarquização do pensamento e uma condição de poder sobre o que pode ou não ser revelado -, desloca/desconstrói a ideia do processo de arquivamento como um sistema fechado, criticando a concepção clássica de arquivo. Segundo o autor, o problema está na redução do arquivo a uma mera experiência da memória, a um retorno à origem, pois, para além das questões epistemológicas, o arquivo pressupõe questões éticas e políticas.

Um terceiro sentido da palavra arkhé pode indicar ainda, em grego, morada, casa dos 
arcontes - antigos magistrados gregos que detinham o poder de elaborar e representar as leis , demarcando o limite e a transição do privado (o conhecimento monopolizado e mantido em segredo) para o público (exposição, revelação). "Não há arquivo sem um lugar de consignação, sem uma técnica de repetição e sem uma certa exterioridade; não há arquivo sem exterior" (DERRIDA, 2001, p.22). Um arquivo é também uma técnica de repetição que, no entanto, nunca pode ser (re)vivida da mesma maneira, posto que é agenciada por diversos contextos. É nesse contraponto entre segredo e exposição que cabe refletir a relação entre cinema e mal de arquivo.

Aproximando isso ao campo cinematográfico, pode-se afirmar que o cinema, em sua ampla acepção - abarcando do filme documentário ao considerado puramente ficcional -, serve de suporte ("tela") à exposição de documentos que se cruzam e se organizam, não devendo ser compreendido como um depósito fechado ou um lugar onde se guarda a verdade, mas, ao contrário, como abertura, algo que leva ao que está por vir, sempre em movimento, de modo a ser constantemente modificado no presente e no futuro. Dessa forma, o cinema não tem apenas uma função arquivística com a função de revelar materiais que antes estavam guardados, mas também imprimir rastros que se inserem nos mecanismos da memória e do esquecimento, da identidade e da diferença, da superfície e do subterrâneo. Exemplos desses mecanismos seriam, de acordo com J. Frow (1997), os diferentes efeitos que provocaram as diferentes representações do Holocausto, em filmes (Hitler: a carreer, 1977) e séries televisivas (Holocaust, 1979; Heimat, 1984). Ainda segundo o autor, cada produção (documental/cinematográfica) leva a diferentes direções, assim, as visões a respeito do Holocausto constroem-se e reconstroem-se como objeto de memória pública de acordo com as questões políticas, os medos e as fascinações do momento em que são produzidas, o que o autor denomina "collective act of remembrance" (FROW, 1997, p. 242-243).

Sendo o cinema uma forma de arquivo, como poderia ele, exposto a um público, manter sua condição de segredo? Essa indagação, quebrando a noção clássica de arquivo, torna-se pertinente porque os meios de comunicação (entre eles o cinema), sobretudo no mundo atual, devido à facilidade de acesso às informações, expõem-nas cada vez mais, revelando e projetando diversos significados possíveis. Os arquivos, portanto, são ressignificados, como se fossem organismos em movimento, com vida e, consequentemente, em processo de modificação constante (SOLIS, 2014). Conforme os contextos sociais e históricos mudam, muda também o valor das coisas, não podendo um arquivo ser mera memória ou apenas referência ao passado. Um arquivo, para Derrida, não tem a função de registrar data, começo e fim de uma história, mas de movimentar-se por uma pulsão de repetição e esquecimento: 
[o mal de arquivo] não apenas apagaria o arquivo constituído na sua positividade patente, mas seria, ainda e fundamentalmente, a condição de possibilidade para que o processo de arquivamento pudesse continuar posteriormente e ser então reiterado ao infinito. Seria a dimensão constituinte do arquivo que se destacaria pelo enunciado do mal de arquivo. Portanto, a constituição do arquivo implicaria necessariamente o apagamento e o esquecimento de seus traços, condição necessária para sua própria renovação. (BIRMAN, 2008, p.110).

Como, afinal, associar o mal de arquivo ao campo do cinema? Ora, o arquivo adquire determinado significado dependendo do arquivista. Sendo o cinema um arquivo, pode-se considerar, de certa forma, que os cineastas são arquivistas, portanto, arcontes que transmitem segredos e fazem a intersecção entre o privado e o público, já que, inseridos em um contexto, cabe a eles interpretar fatos (segundo sua historicidade e posição política) e, a partir disso, desenvolver seus discursos, expondo suas questões e pensamentos a respeito da sociedade. Assim,

A estrutura técnica do arquivo arquivante determina também a estrutura do conteúdo arquivável em seu próprio surgimento e em sua relação com o futuro. $\mathrm{O}$ arquivamento tanto produz quanto registra o evento. É também nossa experiência política dos meios chamados de informação. (DERRIDA, 2001, p. 29).

Tal qual a própria obra de Derrida, o cinema não se apresenta como um marco inicial, um monumento, mas um recorte inacabado, em aberto de algo que está por vir. Em texto que cita Paul Ricoeur, Jeanne Marie Gagnebin afirma:

Ricoeur propõe, então, substituir a ideia de referência por aquela, mais ampla, de refiguração e de desdobrar essa noção: 'a ficção remodelando a experiência do leitor pelos únicos meios de sua irrealidade, a história o fazendo em favor de uma reconstrução do passado sobre a base dos rastros deixados por ele'. (GAGNEBIN, 2006, p.43).

Essa refiguração parece consoante à ideia de "mal de arquivo", pois tanto o arquivista (arconte do cinema) como o público (espectador/leitor) não tratam o arquivo (o cinema) como simples experiência de rememoração, mas, de acordo com Derrida, como uma pulsão que apaga traços inscritos e possibilita novas inscrições no arquivo. Deixam-se, assim, rastros que inscrevem uma lembrança de algo que não existe e que corre o risco de se apagar definitivamente (GAGNEBIN, 2006).

Boi neon, de Gabriel Mascaro, pode ser lido a partir dessa pulsão. O filme explora a história fictícia do vaqueiro de curral Iremar, responsável por cuidar dos animais que participam das conhecidas vaquejadas nordestinas. De cidade em cidade, viajando dentro de um caminhão dirigido por Galega - sua colega, cuja ocupação se divide entre motorista e dançarina de boate -, o protagonista recolhe, por onde passa, revistas de mulheres e de moda, sobras de panos e restos de manequins, a fim de alcançar seu maior sonho: largar a vida rural 
para ingressar na carreira de estilista de moda no Polo de Confecções do Agreste. Nesse contexto, Gabriel Mascaro revela o quão complexa pode ser a trajetória do sertanejo brasileiro contemporâneo, questionando um universo em transformação e modernização no que diz respeito às discussões de gênero social e estereótipos masculino e feminino.

De acordo com Miskolci (2006), tradicionalmente, a subjetividade da mulher é construída para agradar a um outro, enquanto a do homem, para o domínio de si e do outro. Tal processo rotula a relação de oposição entre os gêneros e enquadra as pessoas a formas corporais socialmente entendidas como masculinas e femininas:

\begin{abstract}
O sistema de gênero que dirige nossa sociedade assenta-se no bio-poder para criar os sexos alojados em corpos que se diferenciam e se opõem e, assim, dão materialidade às representações que justificam a hierarquia que atribui ao masculino o domínio e ao feminino a submissão. O sexo que apresentam como evidência se revela, assim, construção social e histórica. (MISKOLCI, 2006, p. 688).
\end{abstract}

No filme em questão, a dupla jornada de Iremar, entre a rusticidade/brutalidade das atividades agropecuárias e a delicadeza/sensibilidade da indústria da moda, aponta as possibilidades que as personagens pós-modernas assumem, simultaneamente, em suas diversas posições sociais. Os tradicionais e consagrados modelos de identidade são, nesse caso, reinventados, fazendo emergir uma nova cultura que, por sua vez, permite novos laços com o outro. Exemplo disso é a relação entre Iremar e Galega: embora vivam em um ambiente hostil guiado, muitas vezes, pelo instinto desejante e quase animal em que se inserem, não se notam indícios de qualquer aspecto entre eles que não seja uma simples e pura amizade, o que, de certa forma, configura uma relação de igualdade entre ambos, e não de submissão. Também a inquestionável força física de Iremar - típica do universo masculino tradicional que sustenta a ideia de aparência de "macho" - mescla-se com a suavidade e a leveza de seu gosto pela moda feminina, ao passo que Galega, dançarina sensual, detém o domínio das atividades e das ferramentas mecânicas utilizadas para a manutenção do caminhão.

Isso mostra que a quebra de paradigmas pode levar a modificações que, segundo Miskolci (2006), criam subjetividades e estilos de vida diversos os quais, baseados em uma ética mais libertária, produzem novas formas de sociabilidade. "A questão da identidade revela-se crucial, portanto, para modificação de um regime de verdade que insiste em impor o binário como eixo de apreensão e institucionalização do mundo" (SWAIN, 2002, apud MISKOLCI, 2006, p. 688-689.). Nesse aspecto, no filme, observa-se, de maneira não dicotômica, a difusão das representações de gênero social, rompendo com as condições de estereótipo tradicional homem-mulher. 
Essa situação explora temas como memória/esquecimento e momento histórico/identidade cultural, a partir dos quais é possível pensar como as tradições culturais de um nordeste atual, ainda machista e duro (memória enraizada e, de certa forma, estereotipada), são ressignificadas de maneira a quebrar paradigmas (como a inversão dos papéis tradicionais de gênero social, até então baseados no patriarcalismo), inscrevendo no arquivo novos rastros e, por vezes, apagando outros rememorados, a fim de jogar com as noções de memória e sua perda, bem como a noção de criação imaginária, fazendo cineasta e espectador refletirem a respeito de uma memória virtual, que se apoia no passado e indaga o futuro.

\section{CONCLUSÃO}

Boi Neon torna-se fundamental para a compreensão desses temas à medida que se firma em um espaço contemporâneo de desenvolvimento econômico e cosmopolita intensos (MASCARO, 2016b), a região nordeste. Isso significa que as relações humanas são constantemente reorganizadas e ressignificadas de acordo com seus desejos e laços afetivos. Pode-se afirmar, assim, que o cinema tomou posse de experiências até então cristalizadas e tradicionalmente representadas - a exemplo das tradições culturais que definem o homem como forte e trabalhador - e abriu a possibilidade de existência de um homem que, embora culturalmente enraizado, é capaz de introjetar outros valores que modificam sua identidade ao longo do tempo. Nesse sentido, o filme diz muito sobre a transformação do ser humano que, diante de uma paisagem monocromática do sertão nordestino, colore-se $\mathrm{s}^{3}$ com novos tons vindos de seus sonhos possíveis, questionando as noções de identidade e de gênero social.

O filme consegue, assim, relacionar-se não apenas com o contexto nordestino brasileiro, mas com todas as culturas que, em processo de transformação, envolvem relações humanas de modo geral, já que remonta um mundo possível em cujas personagens aproximam-se de um cotidiano real dos espectadores, funcionando como reflexo de um ambiente que, em rápido desenvolvimento, preserva e rompe suas tradições e, consequentemente, contradições.

A questão do corpo em Boi neon também representa bem o momento histórico e identitário das personagens, afinal, elas mantêm tradições culturais e, ao mesmo tempo,

\footnotetext{
${ }^{3}$ A passagem do monocromático ao colorido é uma imagem utilizada pelo próprio diretor ao tratar, em entrevista, das transformações do filme: "[...] Tendo a vaquejada como palco alegórico destas transformações em meio à paisagem monocromática do Nordeste, eu pesquiso as cores que reluzem as contradições do consumo e dilato noções de identidade e gênero em personagens que convivem com novas escalas de sonhos possíveis". (MASCARO, 2016)
} 
inscrevem novos rastros à história. Ao passo que Iremar lida com a sujeira da terra e com o cheiro dos animais, ele sente prazer em vestir-se bem (com roupas sempre limpas) e usar perfume, como retrata uma cena do filme em que ele encomenda tal tipo de cosmético a uma vendedora. Tem-se, na representação do próprio corpo, um estereótipo reiterado que transita entre o vaqueiro rude e o estilista sensível, fazendo do cineasta um arconte que retrata a ambiguidade do homem pós-moderno:

\begin{abstract}
Corpos não são habitados como espaços vazios. Eles estão, em sua espacialidade, também em andamento no tempo: agindo, alterando a forma, alterando a significação - dependendo das suas interações - e a rede de relações visuais, discursivas e táteis que se tornam parte da sua historicidade, de seu passado, presente e futuro constitutivos. (BUTLER, 2004 apud PINTO, 2016, s/n).
\end{abstract}

O futuro por vir também aparece na última cena do filme, quando a ação rotineira do protagonista de cuidar do gado é interrompida, anunciando o fim da história e fazendo com que o espectador/expectador, reticente, tenha suas próprias conclusões sobre o rumo que a vida da personagem teria tomado - um futuro do pretérito em construção a que se refere França (2008). Para a autora, o cinema não só reescreve a memória histórica de um "passado perfeito", terminado e completo, como também deixa lacunas e vazios entre as representações, por isso "estas lacunas entre os filmes não falam do que foi nem mesmo do que deve ser: essas lacunas falam, ou melhor, murmuram o que poderia ter sido" (FRANÇA, 2008, p. 6). Isso gera o que, segundo Derrida, seria a impressão Freudiana, compreendida tanto como marca grafada e escrita quanto como uma impressão sobre quem dela fala a posteriori, neste caso, as próprias hipóteses formuladas pelo espectador/expectador.

O cinema quase sempre reencena uma memória histórica, buscando a ilusão de um passado já concluído e determinado. Ocorre, porém, que, como em Boi neon, há vazios entre as representações que criam lacunas a serem preenchidas e que evocam a memória de um pretérito incompleto, ainda por fazer. "Essas lacunas falam, ou melhor, murmuram o que poderia ter sido" (FRANÇA, 2008, p. 6), por isso o processo de construção da memória é constante e interminável.

Diaz-Quiñones (2016) também remete a reflexões com relação à memória frequentemente associada a tudo o que torna possível a conversação, a fim de ser recuperada em outro momento. Segundo o autor, passado e presente coexistem: "César Andreu Iglesias (1915-76) teve a valentia de assumir o conflitivo da memória. Soube reconhecer que não era possível avançar na busca de novas respostas se não se construísse outra memória." (DIAZQUIÑONES, 2016, p. 232).

Isso ajuda a entender as questões políticas e sociais que perpassam o filme Boi neon. É 
preciso pensar em como os desejos de Iremar constituem-se ao longo do filme de maneira complexa: um vaqueiro que lida com os dejetos do gado e gosta de estar perfumado; um artista sonhador da moda que, no entanto, sequer tem sua sexualidade contestada pelo grupo em que vive; um homem que convive em meio à terra do sertão e importa-se com sua boa aparência e vestimenta. Recolocações, portanto, de um grupo socialmente desfavorecido de acordo com suas raízes históricas (o nordeste pobre, difícil e machista) em um campo cultural e intelectual (o cinema engajado e político) para que memórias sejam (re)escritas e (des)contextualizadas em diferentes perspectivas, passando a um circuito de maior visibilidade e reconhecimento do público - a memória rota, conforme cita Díaz-Quiñones (2016).

\section{REFERÊNCIAS}

BIRMAN, Joel. Arquivo e mal de arquivo: uma leitura de Derrida sobre Freud. Em: Natureza Humana. 10(1): 105-128, jan.-jun. 2008. Disponível em: $<$ http://pepsic.bvsalud.org/pdf/nh/v10n1/v10n1a05.pdf>. Acesso em: 09 nov. 2016.

DERRIDA, Jacques. Mal de arquivo: uma impressão freudiana. Tradução: Claudia de Moraes Rego. Rio de Janeiro: Relume Dumará, 2001.

DÍAZ-QUIÑONES, Arcadio. A memória rota - ensaios de cultura e política. Tradução: Pedro Meira Monteiro. Companhia das Letras, 2016.

FRANÇA, Andréa. O cinema entre a memória e o documental. In: Intertexto. Porto Alegre: UFRGS, v.2, n.19, p.1-14, jul-dez 2008. Disponível em: $<$ http://seer.ufrgs.br/index.php/intexto/article/view/7999/4766>. Acesso em: 09 nov. 2016.

FROW, John. Toute la mémoire du monde: repetition and forgetting. Em: Time and commodity culture - Essays in cultural theory and postmodernity. Oxford. 1997. p. 218-247.

GAGNEBIN, Jeanne Marie. Lembrar escrever esquecer. São Paulo: Editora H34, 2006.

LE GOFF, Jacques. História e memória. Tradução: Bernardo Leitão et al. Campinas, SP: Editora da UNICAMP, 1990.

MASCARO, Gabriel. Boi Neon é um filme sobre a transformação, entrevista a Adalberto Meireles. $\quad$ A tarde, 21/01/2016. Disponível em: $<$ http://atarde.uol.com.br/cinema/noticias/1739123-gabriel-mascaro-boi-neon-e-um-filmesobre-a-transformacao-premium>. Acesso em: 23 abr. 2017.

MASCARO, Gabriel. Gabriel Mascaro, diretor de boi neon, entrevista a Lilian Ambar. Salada de Cinema, 16/01/2016. Disponível em: <http://saladadecinema.com.br/2016/01/16/gabrielmascaro-diretor-de-boi-neon>. Acesso em: 23 abr. 2017. 
MISKOLCI, Richard. Corpos elétricos: do assujeitamento à estética da existência. Em: Revista Estudos Feministas. Florianópolis, 14(3):272, setembro-dezembro 2006. p. 681-693. Disponível em: <www.scielo.br/pdf/ref/v14n3/a06v14n3.pdf>. Acesso em: 22 abr. 2017.

PINTO, Joana Plaza. Performatividade. In: Revista Cult. 2016. Ed. 185. Disponível em: $<$ http://revistacult.uol.com.br/home/2013/11/o-percurso-da-performatividade>. Acesso em: 02 dez. 2016.

SOLIS, Dirce Eleonora Nigro. Tela desconstrucionista: arquivo e mal de arquivo a partir de Jacques Derrida. In: Rev. Filos., Aurora, Curitiba, v. 26, n. 38, p.373-389, jan./jun. 2014. Disponível em: <www2.pucpr.br/reol/index.php/rf?dd99=pdf\&dd1=12731>. Acesso em: 02 dez. 2016.

ZURIAN, Francisco A. Construyendo la representación audiovisual de (nuevas) masculinidades en el audiovisual mainstream norteamericano. In: Diseccionando a Adán: representaciones audiovisuales de la masculinidad. Madri: Síntesis, 2015. Versão Kindle. 